\title{
Case Report: Epidural Abscess Following Obstetric Epidural Anesthesia in Vietnam
}

\author{
Lam Duc Nguyen' \\ Toan Thanh Vo (iD) ${ }^{2}$ \\ Cuong Van Tran' \\ Tam Thi-Thanh Hoang ' \\ Phuoc Xuan $\mathrm{Vu}^{3}$ \\ Kha Dong To iD ${ }^{4,5}$ \\ Ha Thi-Ngoc Doan (D) \\ Anh Duy Nguyen ${ }^{6}$ \\ 'Hanoi Medical University, Hanoi, \\ Vietnam; ${ }^{2}$ Thong Nhat Hospital, Ho Chi \\ Minh City, Vietnam; ${ }^{3}$ Bach Mai Hospital, \\ Hanoi, Vietnam; ${ }^{4}$ School of Medicine, \\ Vietnam National University Ho Chi \\ Minh City, Ho Chi Minh City, Vietnam; \\ ${ }^{5}$ Vietnam National University Ho Chi \\ Minh City, Ho Chi Minh City, Vietnam; \\ ${ }^{6} \mathrm{Hanoi}$ Obstetrics and Gynecology \\ Hospital, Hanoi, Vietnam
}

\begin{abstract}
Epidural abscess after obstetric epidural anesthesia occurs infrequently and may result in severe morbidity. We report a clinical case of an epidural abscess in Vietnam. A 31year-old woman who was in labor was admitted to our hospital and given epidural anesthesia indicated to relieve labor pain. After three hours of anesthesia, cesarean section was indicated for the patient due to signs of fetal failure, the epidural catheter was then used to relieve pain for the first 48 hours postoperatively. On post-partum day 5 she presented with high fever of $39-40^{\circ} \mathrm{C}$, fatigue, stimulation, dyspnea, and lumbar pain. The patient then suffered from sepsis and lower limb paralysis. She was diagnosed with epidural abscess based on the MRI of the lumbar spine. The abscess was treated by surgery for draining and appropriate antibiotics with a satisfactory outcome as she completely recovered her motor function and stable health status.
\end{abstract}

Keywords: epidural abscess, analgesia, cesarean section

\section{Introduction}

Epidural analgesia for labor and cesarean section is considered a safe method of pain relief. However, it might still cause several unfavorable complications, including epidural abscesses, though the rate is low. In Germany, according to a survey in 2004, the incidence of epidural abscess is 1 out of 1930 epidural catheter procedures. $^{1}$ In the USA, the frequency increases from $0.2-1 / 10,000$ annual cases to $2.5-3 / 10,000$ annual cases. ${ }^{2}$ The main consequences are sequelae of permanent neurological deficit and death, of which the death rate ranges from $2 \%$ to $20 \%{ }^{3}$ Moen, V. showed that the rate is $1 / 255,000$ pregnant women undergoing regional anesthesia. ${ }^{4}$ These cases happened mainly because of long duration of catheterization and are worthwhile to be presented due to their unusual clinical features.

\section{Case Report}

A thirty-one-year old with her second pregnancy was admitted to labor ward at 38 weeks of gestation because of premature rupture of the membranes, she had a history of normal first delivery, PARA 1011, no known chronic disease or previous surgery. In the delivery room, when the cervix had dilated 3 centimeters, epidural anesthesia for pain relief was administered. The patient was placed in the sitting C-shaped position and the skin was prepared with betadine solution. After local anesthesia, a needle, $18 \mathrm{G}$ Tuohy, was introduced into the palpationidentified L3-4 interspace, with confirmation by loss of resistance (LOR) technique. The epidural catheter was inserted to a depth of $5 \mathrm{~cm}$ cephalad without
Correspondence: Toan Thanh Vo

Thong Nhat Hospital, I Ly Thuong Kiet Street, Ward 7 Tan Binh District, Ho Chi Minh City, 700000, Vietnam

$\mathrm{Tel}+84918554748$

Email vothanhtoan1990@yahoo.com 
difficulty. A bacterial filter was attached. After a test with $60 \mathrm{mg}$ of Lidocaine was negative, $0.1 \%$ bupivacaine and $2 \mathrm{mcg} / \mathrm{mL}$ fentanyl were infused with $8 \mathrm{~mL} / \mathrm{h}$. The other elements of the procedure were sterile, the anesthetist used a face mask and sterile gloves. However, a sterile gown was not worn during the whole procedure. Three hours later, cesarean section was indicated for the patient due to signs of fetal failure. The anesthetist administered a bolus of $400 \mathrm{mg}$ lidocaine and $100 \mathrm{mcg}$ fentanyl via the bacterial filter for the cesarean section. During surgery, the patient was completely stable and a $3300 \mathrm{~g}$ baby girl was delivered with the first- and fifth-minute APGAR score of 8 and 10 respectively. No surgical or anesthetic complications had been detected at this time. The epidural catheter remained in for the first 48 hours after surgery for infusion of $0.1 \%$ bupivacaine and $2 \mathrm{mcg} / \mathrm{mL}$ fentanyl at $6 \mathrm{~mL} / \mathrm{h}$ through the filter, and was then removed. In the following days, the patient complained of backache that got worse gradually, but no fever was noted. However, on the fifth postoperative day, she had continuous high fever ranging from 39 to 40 degrees Celsius, fatigue, irritation, dyspnea, abdominal distention, backache radiating to the left thigh. General examination showed that she was conscious with a temperature of 39 degrees $\mathrm{C}$ and other vital signs within normal ranges. Neurological examination revealed no motor deficit of the lower extremities, normal tendon reflexes, normal bilateral muscle strength, and negative meningeal syndrome.

Gynecological examination showed a good systaltic uterus and dry incision. The lumbar area at the epidural puncture site was swollen, painful, hot, and red. As shown by serum biochemistry there was prominent infection status with white blood cell count of 16.6G/l, CRP $112.7 \mathrm{mg} /$ $\mathrm{L}$, procalcitonin $0.42 \mathrm{ng} / \mathrm{mL}$. After 7 days, there were signs of increased infection including high fever, fatigue, irritability, regular dyspnea, shortness of breath (30 times/ minute), drainage of pus from the puncture site of epidural anesthesia, tense abdomen; weakness, numbness and sensory disturbances in lower limbs. Results of blood culture showed that the pathogenic bacteria was Staphylococcus aureus. Antibiogram revealed appropriate antibiotics including vancomycin, carbapenem, cephalosporin and quinolone groups.

We then transferred the patient to a hospital capable of spinal surgery where the lumbar spine MRI scan was obtained and showed an abscess at lumbar L3-4 and subarachnoid inflammation (Figures 1 and 2).

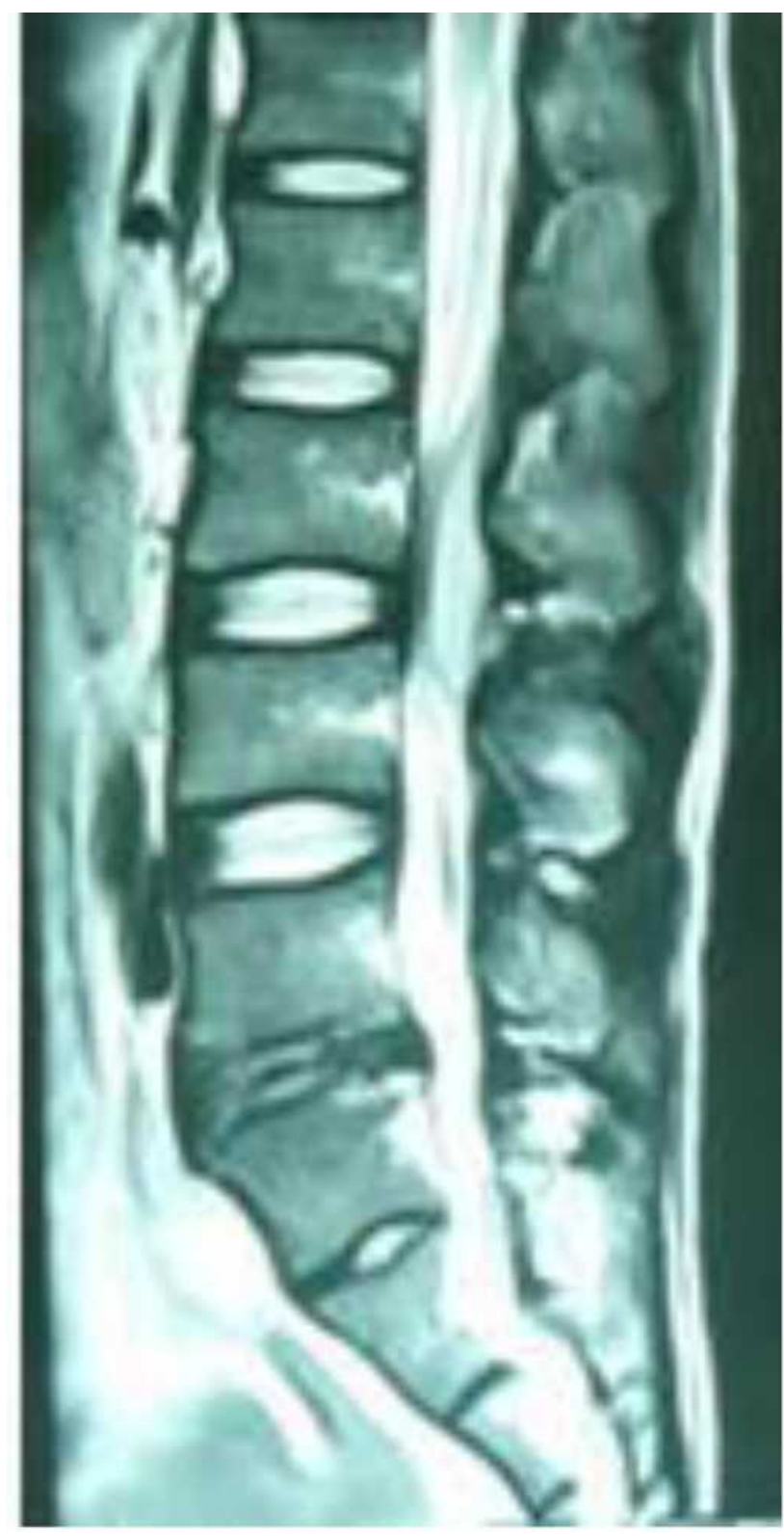

Figure I MRI-longitudinal view, five days after epidural catheter insertion, showing L3-4 epidural abscess (arrow).

Since there were no changes in symptoms in the patient after using antibiotics, after two days, surgery was indicated to remove the absces and, clean the epidural area (Figure 3). Right before surgery, the patient developed numbness and sensory disturbances in lower limbs. Regarding motor deficit, the patient had weakness of muscle strength in lower limbs, ie, 2/5 on the left and $3 / 5$ on the right, as well as reduced tendon reflex of bilateral legs, and negative meningeal syndrome. She was treated with antibiotics according to antibiogram after surgery. 




Figure 2 Axial MRI of lumbar epidural abscess.

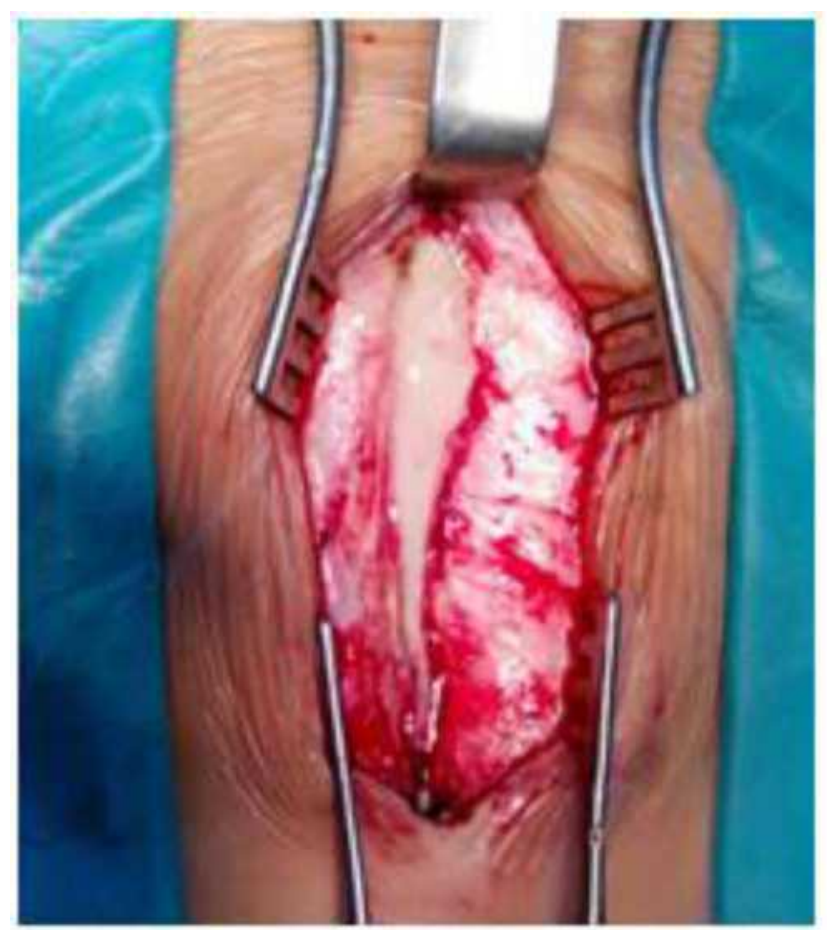

Figure 3 Image of lumbar epidural abscess during surgery.

Five days after neurosurgery, she had completely recovered. She had no fever, fully recovered movement, and had no sensory disturbances.

\section{Discussion}

In general, epidural anesthesia is a good and quite safe method for women during labor and delivery. However, a number of complications can occur after the procedure including epidural abscess, which can develop serious consequences without early identification and treatment. ${ }^{1,2}$

The rate of epidural abscess after epidural anesthesia in obstetrics is very low, yet it ranges widely according to risk factors of the disease. The major risk factor is longterm ( $>3$ days) catheter insertion. ${ }^{3}$ In labor and delivery, the incidence is much lower, about 1 in 506,000 cases $^{4}$ as Tang et al reported, but it has increased slightly recently. ${ }^{5-8}$

In this case, the patient had a prolonged epidural catheterization (51-hours). This would have been the main cause of epidural abscess in our patient. In addition, the sterile condition in the delivery room is not as good as in the operating room. According to Wang et al, the risk factors for developing epidural abscesses were found to be prolonged epidural catheter retention, malignancy, generalized infection, localized infection of the puncture site or immunodeficiency. ${ }^{3}$ Tang et al showed that risk factors might include diabetes, a history of spinal trauma or surgery. ${ }^{4}$ However, a report in Germany showed that epidural abscess appeared after 6 hours of catheterization. ${ }^{6}$

Several causes of epidural abscesses have been identified. According to Goucke, firstly, bacteria might enter the epidural space directly, in case of poor sterility during anesthesia, or absence of facial masks used by the anesthetists. Secondly, bacteria might be present in the anesthetic solution, especially when injecting doses of anesthetic intermittently and prolonged injection to relieve pain after surgery. A third cause could be infection from areas around the epidural site. The fourth cause could be bacteria from the bloodstream due to an infection from another organ to the epidural space. ${ }^{9,10}$ For this patient, the anesthetist washed his hands and wore sterile gloves, hat and face mask during anesthesia procedure. However, he did not wear a sterile gown which is suggested as necessary while inserting epidural catheter, though aseptic preparation is still controversal. ${ }^{11}$ The patient had no back infection or systemic infection, the anesthetic was mixed with reliable sterility and was continuously infused through a bacterial filter.

In terms of clinical presentation, back pain is reportedly the most common symptom in spinal epidural abscess, which accounts for up to $90 \%$ of all cases. ${ }^{4,12,13}$ Meanwhile, it is also a major symptom after every delivery. Thus, if back pain was observed without any clinical 
and subclinical clues of infection, it is easy to leave out the idea of abscess.

To establish clear diagnosis of spinal epidural abscess, MRI is a useful technique. CT myelography has a comparable diagnostic value as MRI but it poses a risk of infecting the subarachnoid space, as it is an invasive method. In our case, the patient underwent MRI and the result helped to establish an accurate diagnosis of epidural abscess. However, our patient was assigned a slightly late MRI of the spine. Early MRI should be indicated in patients with epidural pain relief, with signs of severe infection with no other foci of infection and lower back pain.

S. aureus is one of the most frequent pathogens as its isolation was reported in more than half of epidural abscesses. ${ }^{14}$ Gram-negative bacteria accounted for about $15-20 \%{ }^{4,6,15,16}$ In our case, the organism isolated from both blood and purulent cultures was $S$. aureus. This strain of staphylococcus is sensitive to numerous antibiotics on antibiogram; it also contributes to explaining the patient's good progress after surgery to drain the epidural abscess. The study of Tang et al showed that only 39\% of blood transplants found staphylococcus and $50 \%$ of pus cultures had staphylococcus. ${ }^{4}$ This helps us to identify that early treatment and antibiotic directions are appropriate for the patient. $^{17,18}$

In terms of treatment, internal medicine is preferable if there are no neurological signs detected in patients. ${ }^{19}$ Otherwise, surgery should be indicated immediately for decompression and debridement to avoid severe complications, including death, which was observed in about 50\% of patients. ${ }^{20}$ Although our patient was not diagnosed early with epidural abscess, the pus of the abscess released itself at the needle puncture position in the patient's back, so the patient made quick progress and there was no neurological sequelae.

The lessons learned from our case are: anesthesiologists need to wear surgical gowns to ensure maximum sterility during obstetric epidural anesthesia procedure. The epidural catheter that has been placed for pain relief in labor should not be kept for post-cesarean pain relief because the prolongation of epidural catheter increases the risk of epidural abscess, as the sterile condition in the delivery room is not as good as in the operating room. The pain after cesarean section is usually moderate, and can be managed by injecting a single dose of 2-3 $\mathrm{mg}$ of preservative-free morphine via epidural catheter before withdrawal or by other pain relief methods. It is important to think about complications of an epidural abscess in women with severe back pain accompanied by signs of severe infection. It is necessary to indicate early spinal MRI imaging for diagnosis and early surgery to drain the abscess when the patient has neurological symptoms.

In conclusion, although epidural abscess following epidural analgesia is rare in healthy parturients, it should always be considered if the patient suffers from postoperative severe back pain even without any signs of infection. MRI is efficient support to provide a definitive diagnosis and surgical indication, which is crucial to prevent permanent neurological complications. ${ }^{21-24}$

\section{Ethics Approval and Informed Consent}

Institutional review board (IRB) approval for this study was not required. The patient provided informed consent for the case details and images to be published.

\section{Funding}

This was a non-funded study.

\section{Disclosure}

There are no conflicts of interest.

\section{References}

1. Moen V, Dahlgren N, Irestedt L. Severe neurological complications after central neuraxial blockades in Sweden 1990-1999. Anesthesiology. 2004;101(4):950-959. doi:10.1097/00000542200410000-00021

2. Cook TM, Counsell D, Wildsmith JAW; Royal College of Anaesthetists Third National Audit Project. Major complications of central neuraxial block: report on the Third National Audit Project of the Royal College of Anaesthetists. Br J Anaesth. 2009;102 (2):179-190. doi:10.1093/bja/aen360

3. Wang LP, Hauerberg J, Schmidt JF. Incidence of spinal epidural abscess after epidural analgesia: a national 1-year survey. Anesthesiology. 1999;91(6):1928-1936. doi:10.1097/00000542199912000-00046

4. Tang H-J, Lin H-J, Liu Y-C, Li C-M. Spinal epidural abscess-experience with 46 patients and evaluation of prognostic factors. $J$ Infect. 2002;45(2):76-81. doi:10.1053/jinf.2002.1013

5. Makito K, Mouri H, Matsui H, Michihata N, Fushimi K, Yasunaga H. Spinal epidural hematoma and abscess after neuraxial anesthesia: a historical cohort study using the Japanese Diagnosis Procedure Combination database. Can J Anaesth. 2020. doi:10.1007/s12630020-01827-w

6. Schroeder TH, Krueger WA, Neeser E, Hahn U, Unertl K. Spinal epidural abscess-a rare complication after epidural analgesia for labour and delivery. Br J Anaesth. 2004;92(6):896-898. doi:10.1093/ bja/aeh152

7. Wang LP, Hauerberg J, Schmidt JF. Long-term outcome after neurosurgically treated spinal epidural abscess following epidural analgesia. Acta Anaesthesiol Scand. 2001;45(2):233-239. doi:10.1034/j.13996576.2001.450215.x 
8. Bateman BT, Mhyre JM, Ehrenfeld J, et al. The risk and outcomes of epidural hematomas after perioperative and obstetric epidural catheterization: a report from the Multicenter Perioperative Outcomes Group Research Consortium. Anesth Analg. 2013;116 (6):1380-1385. doi:10.1213/ANE.0b013e318251daed

9. Extradural abscess following local anaesthetic and steroid injection for chronic low back pain - PubMed. Available from: https://pubmed. ncbi.nlm.nih.gov/2145956/. Accessed December 8, 2020.

10. Schröter J, Wa Djamba D, Hoffmann V, Bach A, Motsch J. Epidural abscess after combined spinal-epidural block. Can J Anaesth. 1997;44(3):300-304. doi:10.1007/BF03015368

11. Sellors JE, Cyna AM, Simmons SW. Aseptic precautions for inserting an epidural catheter: a survey of obstetric anaesthetists. Anaesthesia. 2002;57(6):593-596. doi:10.1046/j.13652044.2002.02509_3.x

12. Soehle M, Wallenfang T. Spinal epidural abscesses: clinical manifestations, prognostic factors, and outcomes. Neurosurgery. 2002;51(1):79-85; discussion 86-87. doi:10.1097/00006123-200207000-00013

13. Rosc-Bereza K, Arkuszewski M, Ciach-Wysocka E, BoczarskaJedynak M. Spinal epidural abscess: common symptoms of an emergency condition. A case report. Neuroradiol J. 2013;26(4):464-468. doi:10.1177/197140091302600411

14. Manassero A, Bossolasco M, Carrega M, Coletta G. Postoperative Thoracic Epidural Analgesia: adverse Events from a Single-Center Series of 3126 Patients. Local Reg Anesth. 2020. doi:10.2147/LRA. S272410

15. Danner RL, Hartman BJ. Update on spinal epidural abscess: 35 cases and review of the literature. Rev Infect Dis. 1987;9(2):265-274 doi:10.1093/clinids/9.2.265

16. Xue X, Song J, Liang Q, Qin J. Bacterial infection in deep paraspinal muscles in a parturient following epidural analgesia: a case report and literature review: a CARE-compliant article. Medicine (Baltimore). 2015;94(50):e2149. doi:10.1097/MD.0000000000002149
17. Zhang J-H, Wang Z-L, Wan L. Cervical epidural analgesia complicated by epidural abscess: a case report and literature review. Medicine (Baltimore). 2017;96(40):e7789. doi:10.1097/ MD.0000000000007789

18. Chiang HL, Chia YY, Chen YS, Hung CC, Liu K, Lo Y. Epidural abscess in an obstetric patient with patient-controlled epidural analgesia-a case report. Int $J$ Obstet Anesth. 2005;14(3):242-245. doi:10.1016/j.ijoa.2004.11.003

19. Dysart RH, Balakrishnan V. Conservative management of extradural abscess complicating spinal-extradural anaesthesia for caesarean section. Br J Anaesth. 1997;78(5):591-593. doi:10.1093/bja/78.5.591

20. Khanna RK, Malik GM, Rock JP, Rosenblum ML. Spinal epidural abscess: evaluation of factors influencing outcome. Neurosurgery. 1996;39(5):958-964. doi:10.1097/00006123-199611000-00016

21. Rosero EB, Joshi GP. Nationwide incidence of serious complications of epidural analgesia in the United States. Acta Anaesthesiol Scand. 2016;60(6):810-820. doi:10.1111/aas.12702

22. DeFroda SF, DePasse JM, Eltorai AEM, Daniels AH, Palumbo MA. Evaluation and management of spinal epidural abscess. J Hosp Med. 2016;11(2):130-135. doi:10.1002/jhm.2506

23. Babic M, Simpfendorfer CS, Berbari EF. Update on spinal epidural abscess. Curr Opin Infect Dis. 2019;32(3):265-271. doi:10.1097/ QCO.0000000000000544

24. Huang YY, Zuo Z, Yuan HB, Tsou MY, Chen MT, Tsai SK. A paraspinal abscess following spinal anaesthesia for caesarean section and patient-controlled epidural analgesia for postoperative pain. Int $J$ Obstet Anesth. 2005;14(3):252-255. doi:10.1016/j. ijoa.2005.03.001
International Medical Case Reports Journal

\section{Publish your work in this journal}

The International Medical Case Reports Journal is an international, peer-reviewed open-access journal publishing original case reports from all medical specialties. Previously unpublished medical posters are also accepted relating to any area of clinical or preclinica science. Submissions should not normally exceed 2,000 words or 4

\section{Dovepress}

published pages including figures, diagrams and references. The manuscript management system is completely online and includes a very quick and fair peer-review system, which is all easy to use. Visit http://www.dovepress.com/testimonials.php to read real quotes from published authors. 